\title{
THERMAL ADAPTATION, CAMPUS GREENING AND OUTDOOR USE IN LAUTECH CAMPUS, OGBOMOSO, NIGERIA
}

\author{
ADEDEJI, Joseph Adeniran ${ }^{1) *}$, BELLO, Yekeen Olayiwola ${ }^{2)}$, and FADAMIRO, Joseph Akinlabi ${ }^{3)}$ \\ ${ }^{1)}$ Department of Architecture. The Federal University of Technology, P.M.B. 704, Akure, Ondo State, Nigeria. \\ * Coresponding autor, Email: niranadedeji@yahoo.com \\ ${ }^{2)}$ Department of Architecture. Ladoke Akintola University of Technology P.M.B. 4000, Ogbomoso, Oyo State, Nigeria. \\ Email: layibello@yahoo.com \\ ${ }^{3)}$ Department of Architecture. The Federal University of Technology P.M.B. 704, Akure, Ondo State, Nigeria. \\ Email: joechrisdamiro@yahoo.com
}

\begin{abstract}
The interwoven relationship between the use of indoors and outdoors in the tropics as means of thermal adaptation has long been recognized. In the case of outdoors, this is achieved by green intervention of shading trees as adaptive mechanisms through behavioural thermoregulation. Unfortunately, the indoor academic spaces of LAUTECH campus was not provided with necessary outdoor academic learning environment in the general site planning of the campus for use at peak indoor thermal dissatisfaction period considering the tropical climatic setting of the university. The students' departmental and faculty associations tried to provide parks for themselves as alternatives which on casual observation are of substandard quality and poorly maintained because of lack of institutional coordination and low funding. This study examined the quality and use of these parks for thermal comfort through behavioral adjustment from subjective field evidence with the goal of improvement. To achieve this, twelve parks were selected within the campus. Questionnaires containing use and quality variables were administered randomly upon 160 users of these parks. The data obtained was subjected to descriptive statistical analysis. Results show that the quality of the parks, weather condition, period of the day, and personal psychological reasons of users has great influence on the use of the parks. The study concludes with policy recommendations on improvement of the quality of the parks and the campus outdoors and greenery in general.
\end{abstract}

Keywords: Trees, outdoor furniture, park, users, outdoor use.

\section{INTRODUCTION}

The broad literature on environment-behavior studies is an undeniable bundle of scientific evidence that affirms the affective, perceptive and cognitive interaction between man and his environment at all spatial scales, often to achieve necessary adaptations (Moore, 1979). Indeed, human beings have an amazing ability to adapt and these myriad of possible adaptations is the reason for the survival of human race through outdoor and green values (Indraganti, 2010).

Previous studies on campus outdoor and green space use show that these values include: relieve of stress stemming from the boredom or density of the lessons and provide a place for the academic community to relax, support the relationships between people and increase the quality of university life, behavioural and psychological benefits to campus students, provision of healthy and responsive working and learning environment, promotion of the comfort, convenience and well-being of the students and members of staff with adequate access to natural, calming, beautiful and reposeful sights, among others (Ulrich, 1979; Biddulph, 1999; Abu-Ghazzeh, 1979;
Tzoulas et al., 2007; Fadamiro, 2010). In pursuant of these numerous benefits of outdoor and green use, the present study seeks to examine the use and quality of the departmental/faculty parks on LAUTECH campus which is a major landscape character of the campus constituted by shading trees with outdoor furniture with the goal of improvement for better satisfaction of users.

\section{Environmental Values of Greenery}

The importance of greenery as thermal modifier for indoor and outdoor climate in the built environment of the tropics cannot be over-emphasized. Tress and other vegetation shield people from direct sunlight, block radiant heat loss from homes and people, protect soil and water quality, modify local climate, reduce noise and air pollution (Girling and Kellett, 2005).

According to American Forests (2000), the value of Houston urban forest cooling shade was worth roughly \& 26 million a year in avoided energy costs. It has also been discovered that shading trees improves thermal comfort, the cooling function of tree canopy on parking lot microclimate reduces 
harmful air pollutants emitted by cars and increased tree canopy can reduce asphalt temperature in parking lots by as much as $36^{\circ} \mathrm{F}$ (Shashu-Bar et al., 2010; Scott et al, 1999; Centre for Urban Forest Research, undated). Outdoor thermal environment is impacted by shading trees just as trees and green spaces are elements of the ecosystems that clean air and surface water and provide or renew potable water (Lin et al, 2009; Wolf, 2004). De Dear \& Brager (1998) posits that thermal adaptation can be attributed to three processes of behavioural adjustment, physiological acclimatization and psychological habituation or expectation.

\section{Factors Affecting Outdoor Use}

In the canon of environment and behavior studies, a person's experience of a place is a multivariety phenomenon. While current knowledge affirms the inevitability of the use of outdoors and its associated greenery resources, certain factors often determines, preclude or limits its use. The qualities of the outdoor space like physical/ecological, behavioural/functional quality, aesthetic and visual quality are determinants of the use of outdoors (AbuGhazzeh, 1999). Aydin and Ter (2008) discovered that users' satisfaction, users' expectations, users' characteristics, distance from users' indoor activity areas, cleanliness, comfort, relaxing atmosphere, entertainment potential, proper landscaping and security influence outdoor use of Selcuk University, Turkey. In this gamut, boundaries in particular increases territorial control and therefore regulate interaction with others in outdoor spaces (Taylor, 1988). Sufficient outdoor seating, diversified plant species, attractive water theme, busy work schedule, hot and humid weather, annoying bugs and mosquitoes, small space sizes and long distance was mix of factors in varying degrees that Yang and Stephen (2009) discovered hinders the use of green spaces of the University of Hong Kong. On the whole, "improvement of microclimatic conditions in urban spaces can enable people to spend more time outdoors" (Aijawabra \& Nikolopoulou, (2010) and the "use of outdoor spaces in a university campus is based on associated or anticipated behaviour at a given locus, and the physical parameters of the setting in relation to global cognition of the campus arrangement (Abu-Ghazzeh, 1999, cited in Unlu et al, 2009).

\section{Environmental Values of Greenery}

The importance of greenery as thermal modifier for indoor and outdoor climate in the built environ- ment of the tropics cannot be over-emphasized. Tress and other vegetation shield people from direct sunlight, block radiant heat loss from homes and people, protect soil and water quality, modify local climate, reduce noise and air pollution (Girling and Kellett, 2005).

According to American Forests (2000), the value of Houston urban forest cooling shade was worth roughly \& 26 million a year in avoided energy costs. It has also been discovered that shading trees improves thermal comfort, the cooling function of tree canopy on parking lot microclimate reduces harmful air pollutants emitted by cars and increased tree canopy can reduce asphalt temperature in parking lots by as much as $36^{\circ} \mathrm{F}$ (Shashu-Bar et al., 2010; Scott et al, 1999; Centre for Urban Forest Research, undated). Outdoor thermal environment is impacted by shading trees just as trees and green spaces are elements of the ecosystems that clean air and surface water and provide or renew potable water (Lin et al, 2009; Wolf, 2004). De Dear \& Brager (1998) posits that thermal adaptation can be attributed to three processes of behavioural adjustment, physiological acclimatization and psychological habituation or expectation.

\section{Factors Affecting Outdoor Use}

In the canon of environment and behavior studies, a person's experience of a place is a multivarietye phenomena. While current knowledge affirms the inevitability of the use of outdoors and its associated greenery resources, certain factors often determines, preclude or limits its use. The quality of the outdoor space likes physical/ecological, behavioural/functional quality, aesthetic and visual quality is determinants of the use of outdoors (Abu-Ghazzeh, 1999). Aydin and Ter (2008) discovered that users' satisfaction, users' expectations, users' characteristics, distance from user indoor activity areas, cleanliness, comfort, relaxing atmosphere, entertainment potential, and proper landscaping and security influence outdoor use of Selcuk University, Turkey. In this gamut, boundaries in particular increases territorial control and therefore regulate interaction with others in outdoor spaces (Taylor, 1988). Sufficient outdoor seating, diversified plant species, attractive water theme, busy work schedule, hot and humid weather, annoying bugs and mosquitoes, small space sizes and long distance was mix of factors in varying degrees that Yang and Stephen (2009) discovered hinders the use of green spaces of the University of Hong Kong. On the whole, "improvement of microclimatic conditions in urban spaces can enable people to spend 
more time outdoors" (Aijawabra \& Nikolopoulou, (2010) and the "use of outdoor spaces in a university campus is based on associated or anticipated behavior at a given locus, and the physical parameters of the setting in relation to global cognition of the campus arrangement (Abu-Ghazzeh, 1999, cited in Unlu et al, 2009).

\section{LAUTECH CAMPUS OUTDOOR GREEN QUALITY: AN OVERVIEW}

The Total land mass of Ladoke Akintola University of Technology (LAUTECH campus as indicated in the physical planning (master) plan (figure1) of the campus is 9880.771 hectares. Out of this, only a small percentage, 246.272 hectares (2.49 $\%$ ) as shown in figure 2 have been explored. The land use of this area includes Academic zone and agricultural demonstration/research/training/farm. Just like a city, LAUTECH campus consist of the five major elements of the city-paths, nodes districts, landmarks and edges (Lynch, 1960) and a total students and staff population of about 30,000. All the five elements are properly enriched with green quality of shading trees, plant hedges, undergrowths, grass lawns and flowering plants both "natural" and cultivated. While the departments/faculties and other academic activity areas like library and lecture theatres are akin to districts of the city, a major outdoor characteristic of these districts are their outdoor parks constituted as designed sitting area under groups of trees in each district, constructed and maintained by departmental/faculty students' associations. In addition to this, LAUTECH campus has two other green resources namely the Campus Forest Park which is a wide forest (XIII in figure 2) within the academic and administrative zones and the ceremonial ground near the Ogbomoso-Ilorin road boundary of the campus which is not as thick as the former. A psychological feature of the Campus Forest Park is that it is usually lonely being expansive and physically inadequately kept and only those who desire extreme seclusion at one time or the other uses it for such purpose.

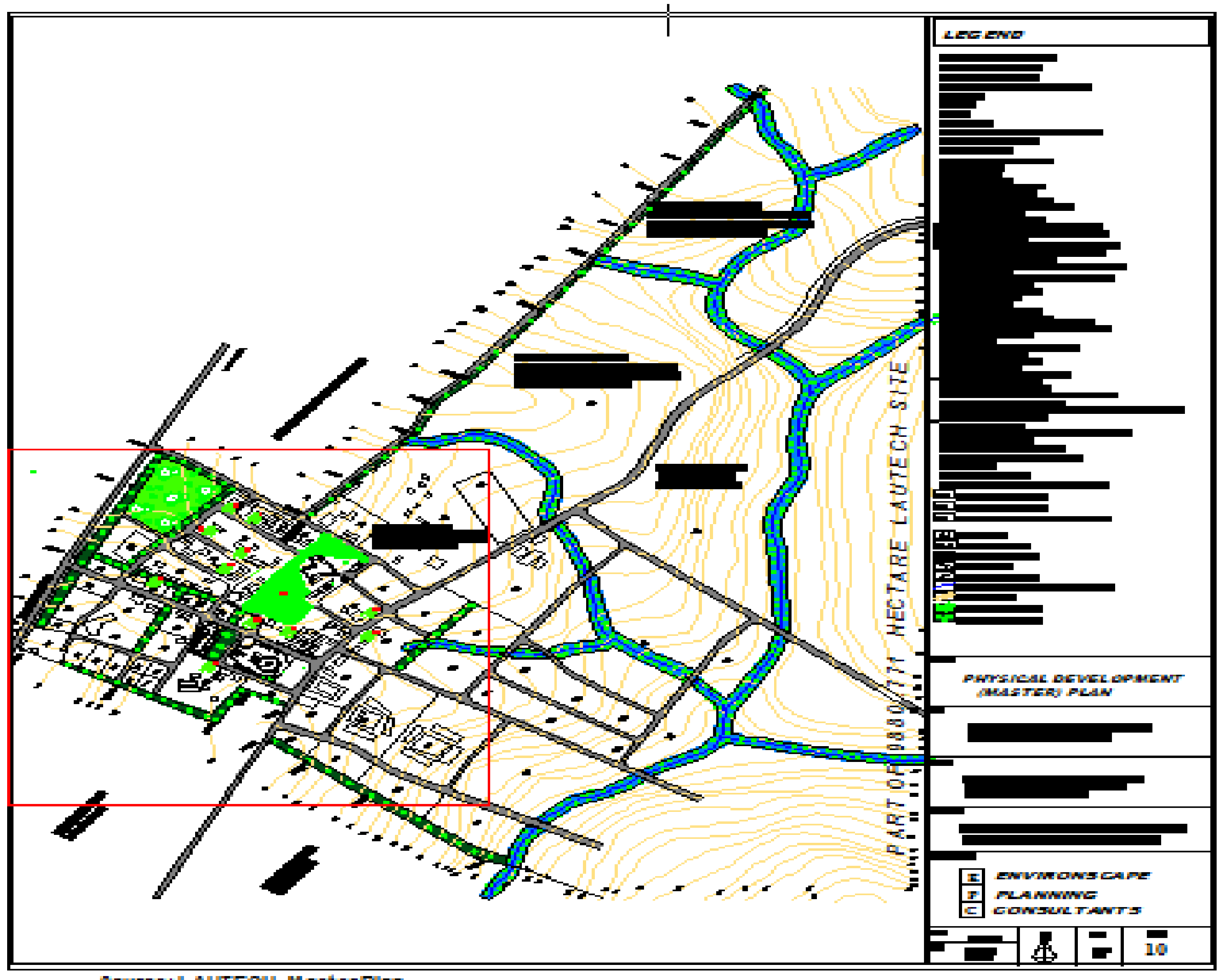

Bouros: LAUTECH Master Plan.

Figure 1. Physical Development (Master plan) LAUTECH Campus 


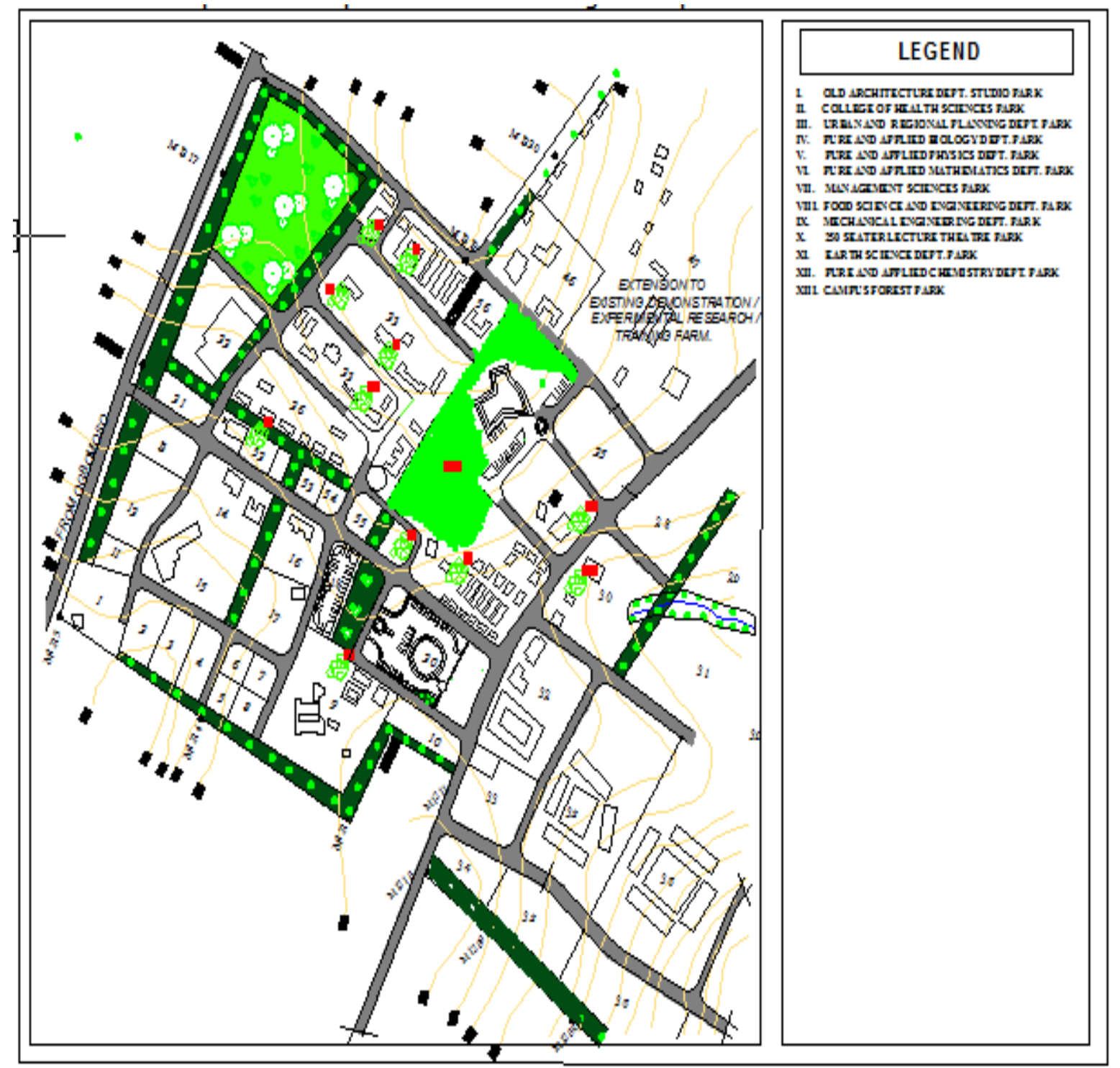

Source: LAUTE CH Master Plan (adapted by Authors, 2010.)

Figure 2. Physical Development (Master plan) of LAUTECH Campus and Forest Park

\section{METHODOLOGY OF STUDY}

In order to examine the use and quality of the parks, twelve of them located at old Architecture Department studio, Faculty of Engineering and Technology (plate 1), College of Health Sciences (plate 2), Urban and Regional Planning Department, Pure and Applied Biology Department, Pure and Applied Physics Department, Pure and Applied Mathematics Department, Faculty of Management Sciences (plate 3), 250 Seat Lecture Theater, Earth Sciences.

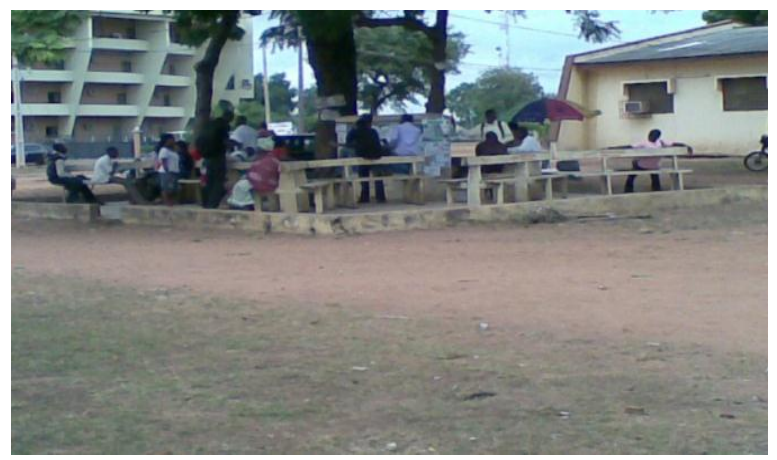

Plate 1. Showing Faculty of Engineering \& Technology Park 


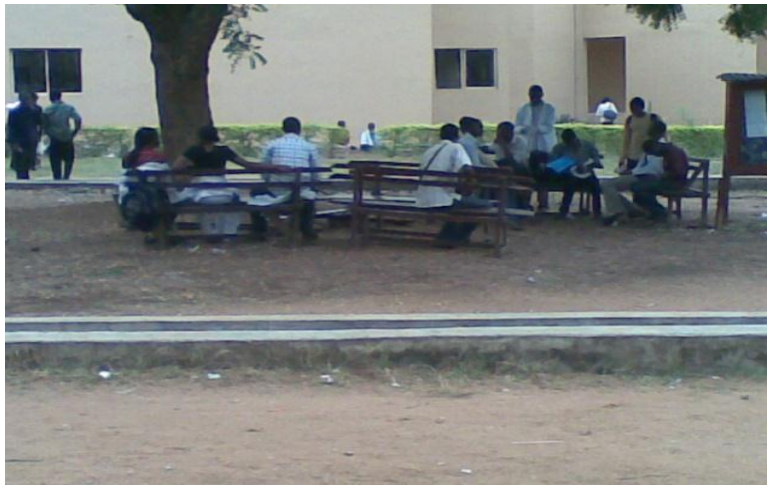

Plate 2. Showing College of Health Sciences Park

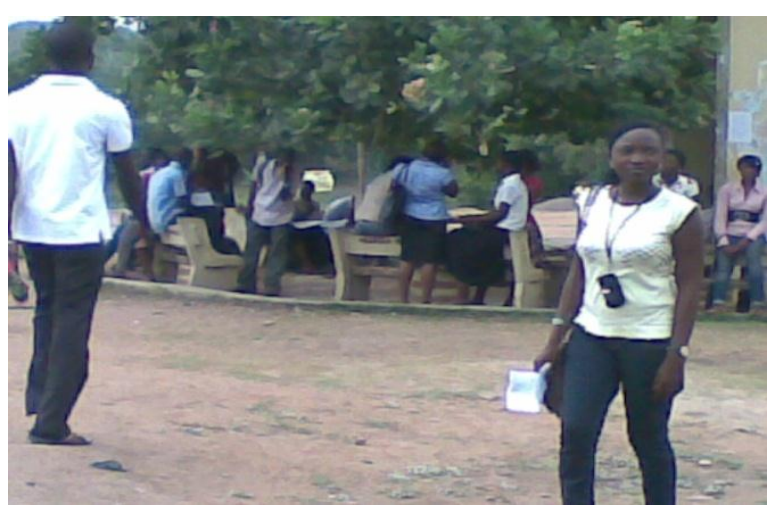

Plate 3. Showing Faculty of Management Sciences Park

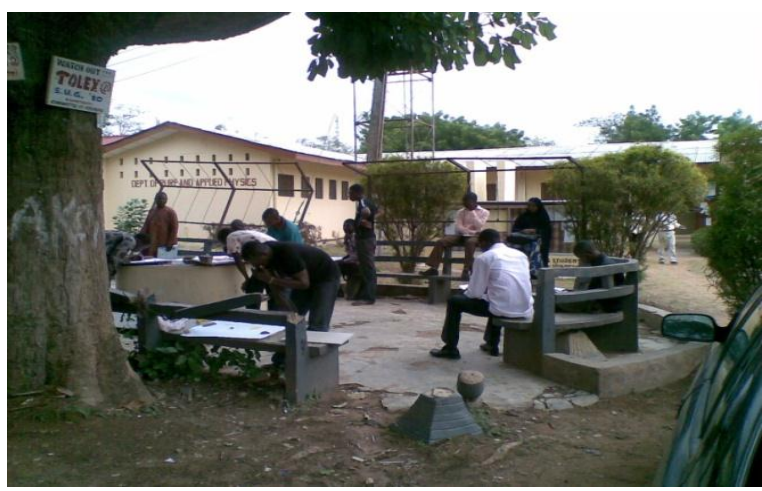

Plate 4. Showing Pure and Applied Chemistry Dept. Park

Department and Pure and Applied Chemistry Department (plate 4). In addition, because of the uniqueness of the Campus Forest Park, it was also selected as the thirteenth park for the study. Questionnaire containing use and quality variables on the parks were randomly administered by the 600 level students of the Department of Architecture on 160 users of the parks during the raining season of 2010 who are generally students. The method of assessment as contained in the questionnaire was subjective and the satisfaction levels of the respondents with the use and quality variables of the parks and outdoors generally was rated on a 5-point Likert scale ranging between social

\section{DISCUSSION OF RESULT}

\section{Characteristics of respondents}

Out of the 160 questionnaires administered (Figure 3), only 155(96.9\%) consisting of 89 males $(57.1 \%)$ and 66 females $(43.3 \%)$ were recovered (Figure 4) whose age distribution are as follow (Figure 5): less than 18 years, 12(7.7\%); 18-20 years $35(22.6 \%)$; $20-25$ years, $73(47.1 \%), 25-30$ years, 30 (19.4\%); above 30 years, $5(3.2 \%)$.

The faculty distribution of the respondents (Figure 6) is: Environmental Sciences, 33(21.2\%); Agricultural Sciences, 23(14.8\%); Engineering and Technology, 37(23.9\%); Pure and Applied Sciences, 17(11.0\%); Management Sciences, 17(11.0\%); Health Sciences, 26(16.8\%). Furthermore, the level distribution of the respondents (Figure 7) is: Pre-degree Sciences, 9(5.8\%); 100-300 levels, 65(40.6\%); 400 level, 38(24.5\%); 500 level, 25(16.1\%); 600 level and above (post graduate), 18 (11.6\%).

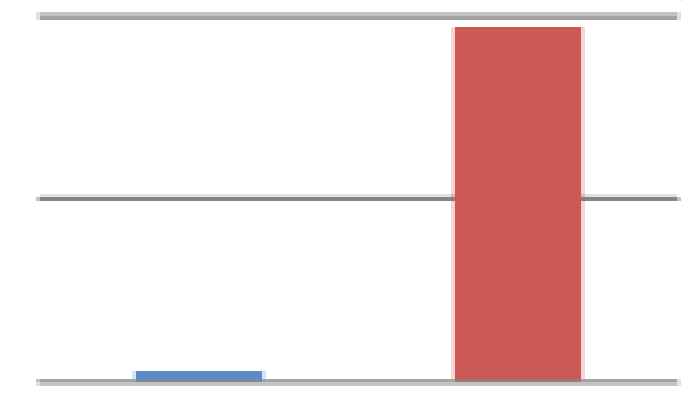

Figure 3. Questionnaire Recovery

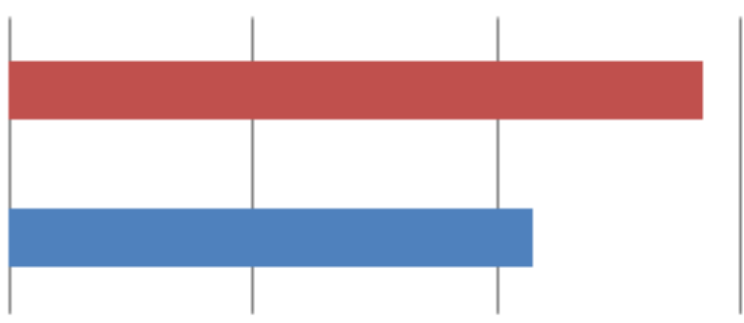

Figure 4. Gender of Respondents

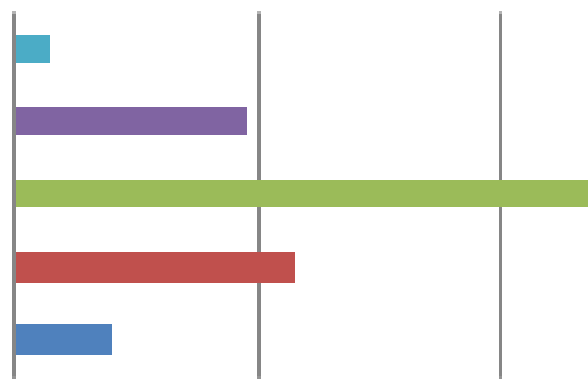

Figure 5. Age distribution of Respondents 


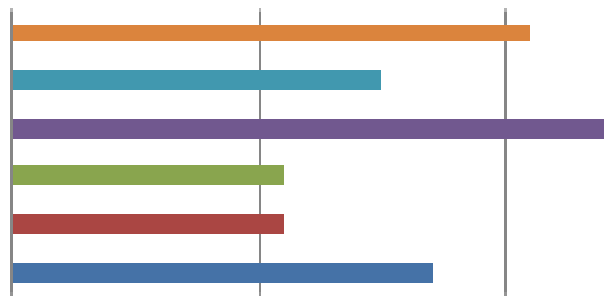

Figure 6. Faculty distribution of Respondents

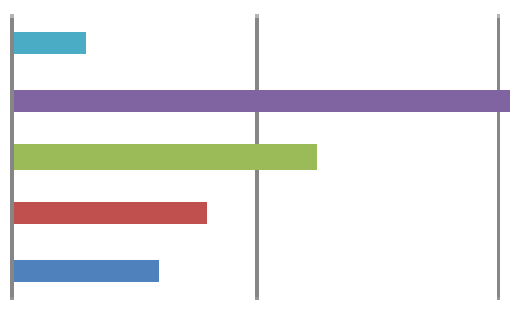

Figure 7. Level distribution of Respondents

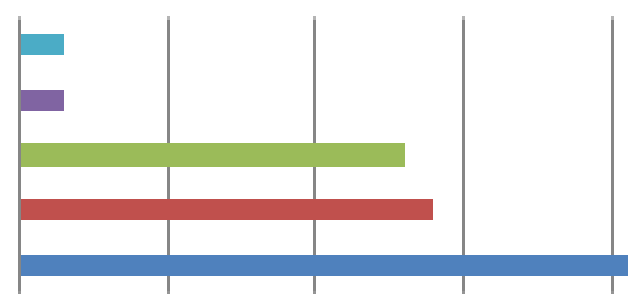

Figure 8. Purpose of use of Departmental/Faculty parks

\section{Outdoor use of the parks}

\section{Purpose of use}

The study reveals that the respondents use the parks generally for the following purposes in ascending order (Figure 8): personal prayer/meditation, 4(2.6 $\%$ ); group prayer/worship 4(2.6\%); group discussion, 40(25.8\%); reading/personal study, 44(28.4\%); relaxation, 63(40.6\%). This pattern shows the importance of the parks as necessary outdoor rooms for individual and group users for range of purpose including academic, religious and recreational. Bearing the peculiarities of the Campus Forest Park as mentioned earlier in mind, the respondents who were sampled in the twelve departmental/faculty parks under study were specifically asked about their purpose of ever using the park. Their response shows a different pattern. The Campus Forest Park provides more privacy being socio-frugal compared with all the other parks that are socio-petal in contrast and offers less privacy. This is clearly obvious in the use of the Campus Forest Park (Figure 9) as follow in ascending order: group discussion, 16(10.3\%); personal prayer/ meditation, 19(12.3\%); social interacttion, 20(12.9\%); group worship, 21(13.5\%); relaxation, 26(16.8\%); personal study, 47(30.3\%) while 6(3.9\%) did not respond to this question. While the highest, $63(40.6 \%)$ use of the twelve other parks was for relaxation being in the places with usually many people, the highest, 47(30.3\%), of the Campus Forest Park was for personal study being more secluded.

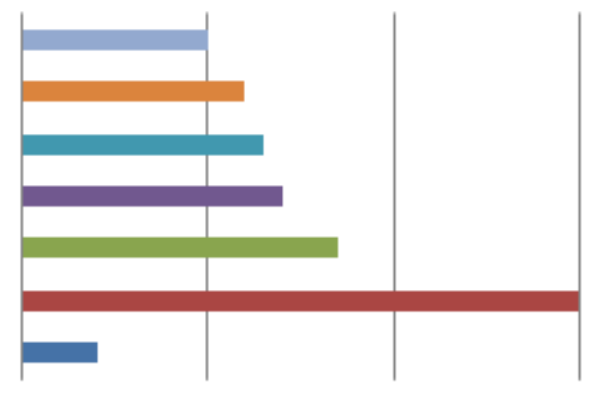

Figure 9. Purpose of Use of Campus Forest Park

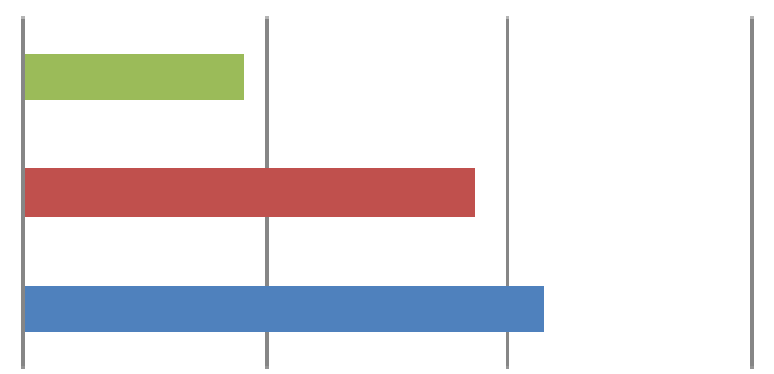

Figure 10. Frequency of Outdoor Use

\section{Frequency and period of outdoor use}

The frequency of the use of outdoors (Figure 10) in the campus generally and specifically the parks was revealed by the study that $28(18.0 \%)$ uses the parks frequently, 57(36.8\%) uses the parks every day and $66(43.6 \%)$ uses the parks occasionally, in ascending order. Even though, 66(42.6\%) being the highest indicate that they only use the parks occasionally, their number is outweighed by the addition of frequent and everyday uses of the parks, 85(54.8\%) which emphasizes the general significance of the outdoor and the par the parks in particular in the campus life.

The period of use of the parks (Figure 11) as revealed by the study are morning, 28(18.0\%); afternoon, 55(35.5\%); evening, 37(23.9\%); every time, $33(21.3 \%)$; while $2(1.3 \%)$ did not indicate their response. The highest number of people, 55 (35.5\%), uses the parks in the afternoon and when this is added to the number that uses the parks every time (definitely this includes afternoon in addition to regular afternoon uses) a total of $88(76.8 \%)$ people uses the parks in the afternoon. Since afternoon is the hottest periods in the tropics, these users are engaged 
in the use of outdoors as means of environmental adaptation and thermal adaptation in particular. Furthermore, the naturally occurred pattern that students are found using the outdoors every period of the day no matter their busy schedule is not accidental but premised upon the interwoven relationship between the use of outdoors and indoors as means of environmental adaptation.

The reasons for employing the parks for outdoor use (Figure 12) was revealed by the study as follow: the outdoor climate is conducive, $68(43.9 \%) ; 17(10.9 \%)$ says that the indoor climate is not conducive while $70(45.2 \%)$ uses the outdoors because it provides more social interaction for them. This implies that a total of $85(54.8 \%)$ respondents use the outdoor for climatic reasons as means of environmental adaptation.

The study also draws a comparison between indoors and outdoors generally based on weather condition and concern for personal space (Figure 13). In the aspect of weather condition, 64(41.3\%) prefers the indoor to outdoor because of lack of privacy that results in disturbance from other outdoor users while $8(5.2 \%)$ prefer indoors claiming that outdoor users may be victims of crime like theft. The study reveals the following reason why they do not even use the Campus Forest Park (Figure 14): loneliness, 46(37.1\%), fear of crime, 15(12.1\%); unfavorable weather like rain, 26(21.0\%); fear of dangerous animals, 37(29.8\%); not indicated, 32(20.5\%).

It is very clear again from this pattern that only people who seeks extreme seclusion uses the campus forest park while fear of dangerous animals, in the parks is significant because of the thick foliage.

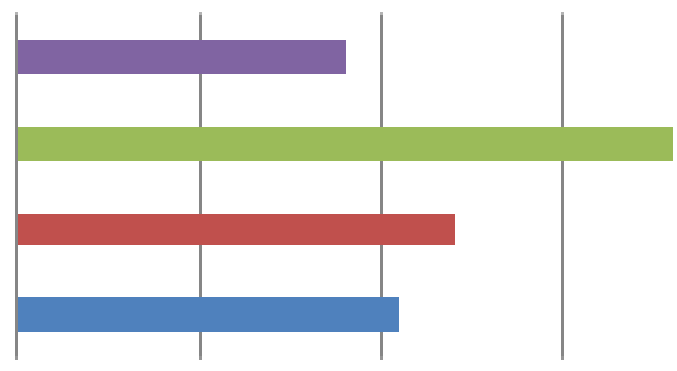

Figure 11. Period of Use of Parks

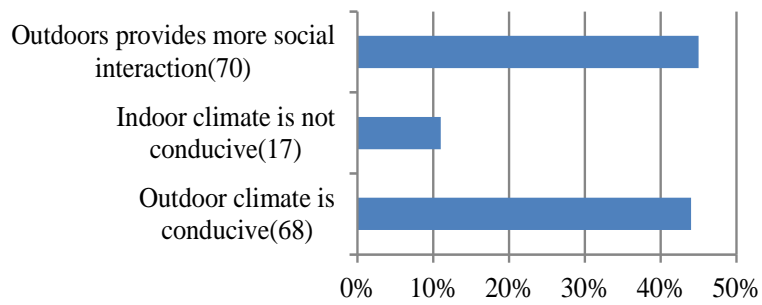

Figure 12. Reasons for Outdoor/Parks Use

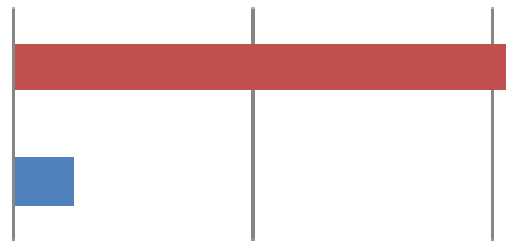

Figure 13. Reasons for Preferring Indoors to Outdoors

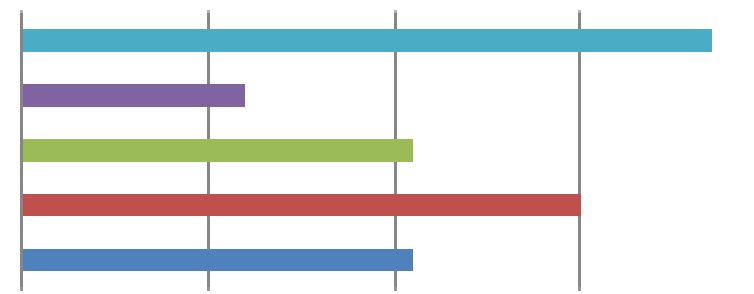

Figure 14. Reasons for not using the Campus Forest Park

\section{Quality of the parks and outdoors generally}

\section{Outdoor furniture}

These are constituted by seats and tables. $141(91.0 \%)$ reported that there were seats in their parks while $14(9.0 \%)$ reported there was no seat in their parks (Figure 15). In the case of tables (Figure 16), there are less compare to seats as only $31(20.3 \%)$ indicated that they had tables while the largest percentage, 124 (79.7\%) said they had none.

The construction materials of the seats and tables (Figure 17) are reported by the respondents as follow in ascending order: steel, 3(1.9\%); concrete/timber, 33(21.5\%); timber only 40(25.8\%); concrete only, $67(43.2 \%)$ while $12(7.7 \%)$ did not answer the question. It is reasonable that concrete is the most widely used material being adaptable to weather conditions and very durable for outdoor use although may be hot to touch during hot afternoons while steel was the least reported being highly susceptible to rusting especially for outdoor purpose. Table 1 below shows how satisfied the respondents are on the quality of the seats.

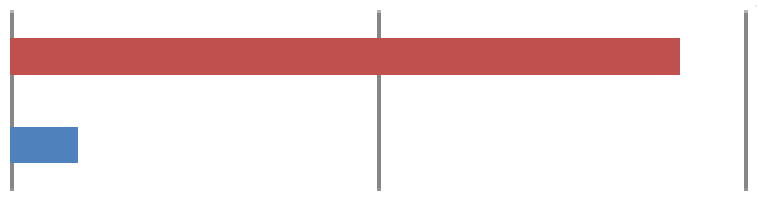

Figure 15. Availability of Park Seats

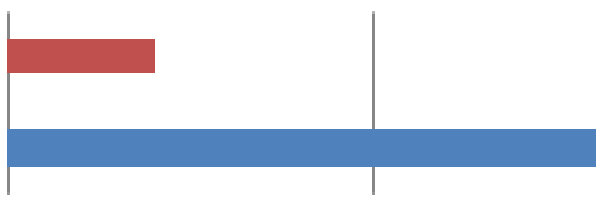

Figure 16. Availability of Park Tables 


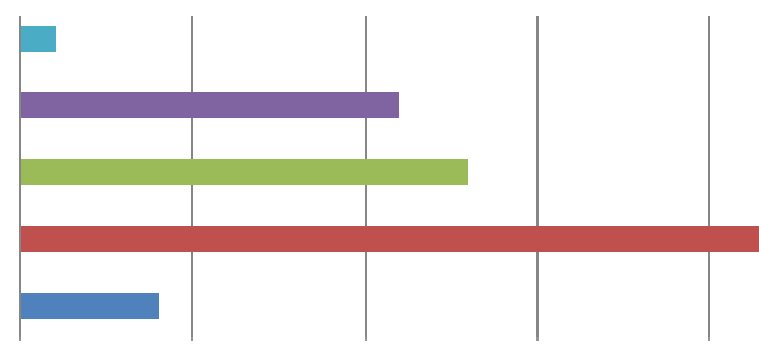

Figure 17. Construction Materials of Parks' Seats and Tables (Outdoor furniture)

Table 1. Park users'satisfaction with the seats

\begin{tabular}{lcccc}
\hline & Frequency & Weight & $\begin{array}{c}\text { Percent. } \\
\text { Cumulative } \\
\text { percent. }\end{array}$ \\
\hline Very satisfied (5) & 12 & 60 & 7.7 & 7.7 \\
Satisfied (4) & 52 & 208 & 33.5 & 41.2 \\
Undecided (3) & 18 & 54 & 11.6 & 52.8 \\
Fairly satisfied (2) & 47 & 94 & 30.3 & 83.1 \\
Not satisfied (1) & 19 & 19 & 12.3 & 95.5 \\
Not indicated & 7 & 0 & 4.5 & 100.0 \\
Total & 155 & 435 & 100 \\
\hline \multicolumn{5}{c}{ Mean (x) $=435 / 155=2.8$} \\
Source: Authors' field survey, 2010
\end{tabular}

The mean $(\mathrm{x})$ satisfaction of the respondents with the seats is low having a value of 2.8 which is between undecided (3) and fairly satisfied (2). This could hinder some students from maximizing the use of the parks because of lack of comfort.

\section{Green quality}

The green quality of the parks and the campus in general are constituted by trees, grass lawn and plant hedges. Table 2 shows the users' satisfaction with trees on the campus.

The mean (x) of the overall satisfaction level is 3.5 which tends towards the satisfaction side, Being evident in ordinary observation of the trees. Concerning plant hedges round the parks (Figure 18), $88(56.8 \%)$ respondents reported that it was available at the parks while $67(43.2 \%)$ reported that it was not available, a situation that leads to complete loss of visual privacy at the parks.

Table 2. Park and outdoor users' satisfaction with quantity (shading) and quality of trees.

\begin{tabular}{lcccc}
\hline & Frequency & Weight & Percent. & $\begin{array}{c}\text { Cumulative } \\
\text { percent. }\end{array}$ \\
\hline Very satisfied (5) & 16 & 80 & 10.3 & 10.3 \\
Satisfied (4) & 89 & 356 & 57.4 & 67.7 \\
Undecided (3) & 15 & 45 & 9.7 & 77.4 \\
Unsatisfied (2) & 28 & 56 & 18.1 & 95.5 \\
Very unsatisfied (1) & 7 & 7 & 4.5 & 100.0 \\
Total & 155 & 544 & 100 & \\
\hline \multicolumn{4}{c}{ Mean $(\mathrm{x})=544 / 155=3.5$}
\end{tabular}

Source: Authors' field survey, 2010
The study assessed users satisfaction of the grass lawns in terms of quality (maintenance) and quantity follow: very satisfied, 16(10.3\%); satisfied, 48(31.0\%); undecided, 23(14.8\%); not satisfied, 64(41.3\%); not indicated, $1(0.6 \%)$. This four point likert scale between 4 (very satisfied) and 1 (not satisfied) gives a mean (x) of 2.1 which is below satisfaction level of 3 . The implication is that the grass lawns deserved to be improved upon to complement the good quality trees for balanced green resources. Despite the construction of see-through two-line twisted-wire fence round the edge of the lawns, the study discovered that the grass lawns are often crossed by the respondents as follow (Figure 19): frequently, 30(19.4\%); thrice, 7(4.5\%); twice, 17(11.0\%); once, 24(15.5\%); never, 74(47.7\%); not indicated, 3(1.9\%).

This result is an aftermath of the lack of satisfaction of the users with the layout and treatment of the footpaths/walkways on the campus landscape as shown in table 3 where the mean $(\mathrm{x})$ satisfaction level is 2.8 which is tending towards unsatisfaction. Obviously, the use of wire fence cannot control the pedestrian circulation of the campus community and properly distributed paved walkways are necessary.

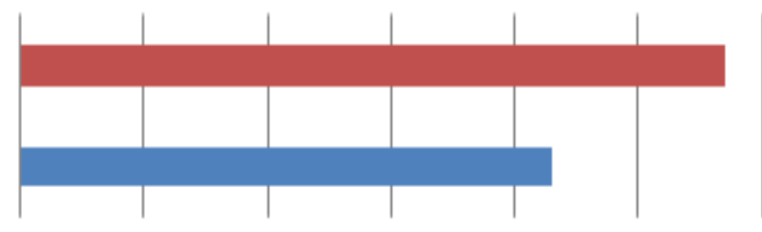

Figure 18. Availability of Plant Hedges at the Parks

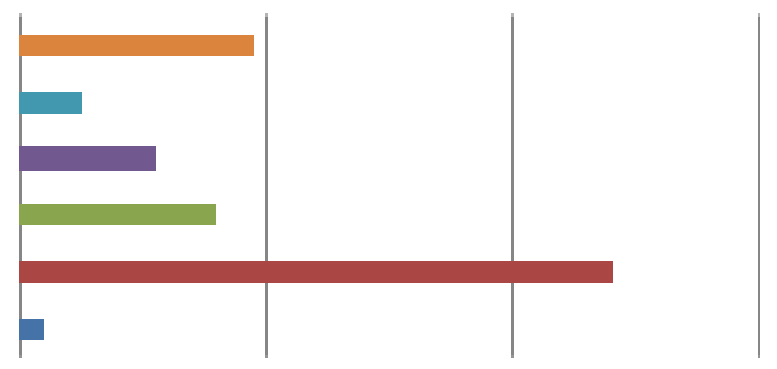

Figure 19. Crossing of Grass Lawns

Table 3. Users' satisfaction which layout and treatment of LAUTECH campus footpaths/walkways

\begin{tabular}{lcccc}
\hline & Frequency & Weight & Percent. & $\begin{array}{c}\text { Cumulative } \\
\text { percent. }\end{array}$ \\
\hline Very satisfied (5) & 9 & 45 & 5.8 & 5.8 \\
Satisfied (4) & 45 & 180 & 29.0 & 34.8 \\
Undecided (3) & 23 & 69 & 14.8 & 49.6 \\
Unsatisfied (2) & 64 & 128 & 41.3 & 90.9 \\
Very unsatisfied (1) & 14 & 14 & 9.1 & 100 \\
Total & 155 & 436 & 100.0 & \\
\hline \multicolumn{5}{c}{ Mean (x)=436/155=2.8 }
\end{tabular}

Source: Authors' field survey, 2010 


\section{Parkfloors}

Only $49(31.6 \%))$ respondents reported that the floor of their parks were concrete paved while the majority, 104(67.2\%) reported that the floor of their packs had no concrete paving and 2(1.2\%) did not answer this question (Figure 20). Even though concrete paving is cheaper and easier to maintain, if it is not interspersed with soft landscape elements, it can breed thermal island at the parks.

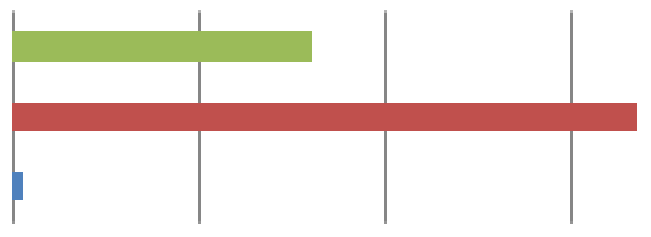

Figure 20. Concrete Paving of Parks' Floors

\section{CONCLUSION AND RECOMMENDATION}

The discoveries of this study can be summarized as follow: The departmental/faculty parks are mostly used for relaxation than any other purposes being closer to lecture rooms and practical studios and affords less privacy. Conversely, the Campus Forest Park is mostly used for personal study being more secluded and distant from departments/faculties. The parks are used every day, frequently and mostly in the afternoons, the outdoor weather being more conducive than indoors except during inclement weather period. Fear of being victim of crime (like theft), dangerous animals, loneliness and rain, hinders students from using the Campus Forest Park efficiently. The outdoor seats and tables were made of concrete more than steel and timber being more easy to maintain and durable compared with others. In fact, the use of steel was very meager. The furniture was not adequate in quality and quantity. The green quality of the parks and the outdoors in general in terms of trees, plant hedges and lawns was generally discovered by the study to be adequate especially the shading trees. However, the layout of the footpaths/ walkways that was not adequate made people to cross the grass lawns though wire barriers were provided against this habit. Furthermore, the use of concrete for parks floor was prevalent and this could breed heat island during hot afternoons and too cold during wet seasons. In view of these discoveries, the following recommendations become necessary:

1. The park trees should be maintained to achieve more shading;

2. The linear elements of the landscape like roads and walkways should be planted with side rows of trees to achieve greenways;
3. The outdoor furniture in the parks should be overhauled and properly designed in a spacing mix to afford some level of privacy and socialization to satisfy peculiar needs of users as may be required;

4. The floor of the departmental/faculty parks should be finished with adequate mix of soft and hard landscape elements while the floor of the Campus Forest Park should be planted with lawn grass and be adequately maintained for safety of users from dangerous animals especially reptiles;

5. The Campus Forest Park should be provided with adequate outdoor seats and tables made of concrete in patches;

6. Hedges should be planted and maintained at adequate heights in all the parks as outdoor walls;

7. Other spots within the campus that has adequate group of shading trees should be converted to general parks similar to departmental ones for the use of the campus community;

8. It was observed that the green quality of the campus was deficient in decorative palms and should therefore be planted in designed patterns;

9. The walkways/footpaths should be re-designed in proper layout to avoid crossing of the lawns and the wire fence barriers should be removed to achieve decent campus outlook;

10. The parks and the outdoors in general should be provided with adequate electric lighting for night use and necessary surveillance.

\section{REFERENCES}

Abu-Ghazzeh, T.M. (1999). Communicating Behavioural Research to Campus Design-Factors Affecting the Perception and Use of Outdoor Spaces at the University of Jordan. Environment and Behaviour, 31(6), 764-804.

Aijawabra, F. \& Nikolopooulous. M. (2010). Influence of Hot Arid Climate on the Use of Outdoor Urban Spaces and Thermal Comfort: Do Cultural and Social Backgrounds Matter? Intelligent Buildings International, 2(3), 198-217. Available:http://ingetaconnet.com/content/earthscan/i nbi/2010/00000002/00000003/art0... [Access on 13-08-2010].

American Forests. (2000). Urban Ecosystem Analysis for the Houston Gulf Coast Region: Calculating the Value of Nature" December.

Aydin, D. and Ter, U. (2008). Outdoor Space Quality: A Case Study of a University Campus Plaza. Archnet-IJAR, International Journal of Architectural Research, 2(3), 189-203 November.

Biddulph, M. (1999). Bringing Vitality to a Campus Environment, Urban Design International, 4 (3 \& 4), 153-166. 
Center for Urban Forest Research. (Undated). Pacific Southwest Research Station, USDA Forest Service, in Eco-Parking.

De Dear, R. \& Brager, G.S. (1998). Thermal Adaptation in the Built Environment: A Literature Review. Energy and Building, 27, 83-96.

Fadamiro, J.A. (2010). Landscape Architecture: Dynamics of City Development "Inaugural Lecture Series 58 Delivered at Federal University of Technology, Akure on Tuesday 18th May, 2010, p. 21-22. Akure, Nigeria.

Girling, C. and Kellet, R. (2005). Skinny Streets and Green Neighbourhoods: Design for Environment and Community. Washington, Island Press.

Indraganti, M. (2010). Adaptive Model of Thermal Comfort. Sci Topics. Available: http://www. scitopics.com/adaptive_model_of_thermal_com fort.html. [Acess on 12-08-2010].

Lau, Stephen S.Y. and Yang, F. (2009). Introducing Healing Gardens into a Compact University Campus: Design Natural Space to Create Healthy and Sustainable Campuses. Landscape Research 34(1), 55-81.

Lin, T.P., Matzarakis, A., Hwang, R.L. (2009). Shading Effect on Long-Term Outdoor Thermal Comfort. In R.L. Hwang, T.P. Lin., Outdoor Thermal Comfort in University Campus in Hot-Humid Regions. The Seventh International Conference on Urban Climate, 29 June - 3 July, 2009, Yokotame, Japan.

Lynch, K. (1960). The Image of the City. Cambridge, Massachusetts: The M.I.T. Press.

Moore, G.T. (1979). Environment and Behaviour Studies. In J.C. Snyder \& A.J. Catanese (Eds.) Introduction to Architecture New York: McGrawHill, 46-71.
Scott, K.I., James R., and McPherson, E.G. (1999). Effects of Tree Cover on Parking Lot Microclimate and Vehicle Emissions, Journal of Aboriculture, 25, 129-141.

Shashua-Bar, L., Pearlmutter, D., Erell, E. (2010). The Influence of Trees and Grass on Outdoor Thermal Comfort in a Hot-Arid Environment. International Journal of Climatology, First Published online in advance of print: 4 Aug, 2010. Available: http://online.library.wiley.com/ doi/10/1002/joc.2177/abstract [Access on 12-082010].

Taylor, R. (1988). Human Territorial Functioning. Cambridge: Cambridge University Press.

Tzoulas, K., Korpela, K., Venn, S., Yli-Pelkonen, V., Kazmierszak, A., Niemela, J. (2007). Promoting Human Health in Urban Areas Using Green Infrastructure: A Literature Review. Landscape and Urban Planning. 81, 167-178.

Ulrich, R.S. (1979). Visual Landscapes and Psychological Wellbeing, Landscape Research, 4, 1723.

Unlu, A., Edgu, E., Cimsit, F., Salgamcioglu, M.E., Garip, E., Mansouri, A. (2009). Interface of Indoor Outdoor Spaces in Buildings, A Syntactic Comparison of Architectural Schools in Istanbul. Proceedings of the $7^{\text {th }}$ International Space Syntax Symposium. Koch D., Marcus L. \& Steen J. (Eds.) Stockholm: KTH.

Wolf, K.L. (2004). Public Value of Nature: Economics of Urban Trees, Parks and Open Space. In D. Miler \& J.A. Wise (Eds.), Design With Spirit: Proceedings of the 35th Annual Conference of the Environmental Design Research Association. (89-92). Edmond, OK: Environmental Design Research Association (edra). 